\title{
Investigation into the mechanical properties of structural lightweight concrete reinforced with waste steel wires
}

Kamran Aghaee

MSc Postgraduate, Department of Civil Engineering, Islamic Azad University, Yazd, Iran

\section{Mohammad Ali Yazdi}

Postgraduate student, School of Naval Architecture, Ocean and Civil Engineering, Shanghai Jiao Tong University, Shanghai, PR China

\section{Konstantinos Daniel Tsavdaridis}

Assistant Professor, School of Civil Engineering, University of Leeds, Leeds, UK

The study of concrete incorporating different waste fibres has started to increase rapidly due to economic reasons and positive environmental effects. In the study reported here, waste steel wires from steel reinforcement and used formworks were blended with structural lightweight concrete, with the aim of replacing commercial steel fibres of controlled quality with recycled fibres. Compression, tensile, flexural and impact tests were performed to assess the mechanical properties of $\mathbf{2 8} \mathrm{d}$ old concrete specimens reinforced with mixed waste steel wires, mixed steel fibres as well as plain concrete. The percentages of fibres examined in the fibre reinforced concrete (FRC) specimens were $0.25 \%, 0.50 \%$ and $\mathbf{0 . 7 5} \%$ (volume fraction of the concrete). With varying fibre contents, similar trends were observed in all the types of FRCs studied. It was thus concluded that waste steel wires could be used as a suitable alternative to industrial steel fibres for structural lightweight concrete applications.

\section{Notation} \\ d diameter of concrete cylinder \\ $I_{5}, I_{10}, I_{20} \quad$ toughness indices \\ $l \quad$ length of concrete cylinder \\ $P \quad$ maximum applied load indicated by the testing \\ machine \\ $R_{5,10}, R_{10,20}$ residual strength factors \\ $T \quad$ splitting tensile strength \\ $V_{\mathrm{f}} \quad$ fibre content (\% volume fraction of concrete)
}

\section{Introduction}

Structural lightweight aggregate concrete (LWAC) has been used in many different applications for several decades, including buildings, bridges, floors and partitions (Shafigh et al., 2011; Yasar et al., 2003). It is a popular material in the construction industry due to its exclusive benefits of tensile capacity, low coefficient of thermal expansion and superior heat and sound insulation capability (Alshihri et al., 2009; Duzgun et al., 2005; Hassanpour et al., 2012; Sengul et al., 2011; Tanyildizi, 2008; Yasar et al., 2003). In construction, the use of lightweight concrete leads to reduced dead load, so earthquake forces are smaller, reduced structural and non-structural member dimensions and thus decreased associated costs (Altun and Aktas, 2013; Duzgun et al., 2005; Libre et al., 2011; Topcu, 1997).

However, the inferior mechanical properties of lightweight concrete have eliminated its use for high load-bearing structural members (Arisoy and Wu, 2008; Gao et al., 1997; Hassanpour et al., 2012). Conventional concrete is a brittle material with low shear capacity and bending strength (Hassanpour et al., 2012; Shah and Ribakov, 2011; Slater et al., 2012; Withers and Bhadeshia, 2001). These characteristics are also apparent in LWAC for the same compressive strength (Balendran et al., 2002; Domagala, 2011) due to the existence of lightweight aggregates that are relatively weaker than the cement matrix; LWAC also has low resistance to crack propagation (Naaman and Reinhardt, 2003). The addition of steel fibres to concrete is beneficial, as this decreases the aforementioned brittleness and spalling (Kandasamy and Murugesan, 2011; Pawade et al., 2011; Wui et al., 2013). The incorporation of steel fibres is also widely used for reducing the brittleness of LWAC (Arisoy and Wu, 2008; Chanh, 2004; Kayali et al., 2003; Pawade et al., 2011).

The properties of steel-fibre-reinforced concrete (SFRC) have been examined in the past and improved tensile strength has been reported (Altun and Aktas, 2013; Mohammadi et al., 2008). It has also been reported that adding steel fibres to lightweight concrete increases the load-carrying capacity while preventing the opening of macro-cracks and reducing the width of microcracks, as well as providing some resistance to dynamic and impact loads (Aslani, 2013; Ghasemi Naghibdehi et al., 2014).

Although many research studies have been conducted on the use 
of steel fibres for reinforcing concrete, it is not the most economical solution. The use of waste fibres arising from, for example, milling, manufacturing machinery and the textile industry is considered an effective alternative (Altun and Aktas, 2013). The reuse of raw waste materials is often seen as the most effective way to 'recycle' waste materials into products that can be used as viable alternatives, thus conserving resources and reducing environmental impacts. In many cases, however, mechanical, chemical or biological procedures are carried out to recycle the waste materials. All these methods are energy consuming and could be environmentally harmful in terms of air, water and soil pollution. The use of raw material such as waste steel wires does not produce these harmful effects, but is environmentally friendly (Süleyman Gökçe and Șimșek, 2013; Wang, 2010).

Wang et al. (2000) conducted studies on the mechanical properties of fibre-reinforced concrete (FRC) using recycled fibres including tyre cords/wires, carpet fibres, feather fibres, steel shavings, wood fibres from paper waste, as well as high-density polyethylene fibres. They reported that concrete with the addition of recovered industrial fibres could have similar mechanical properties to common FRCs, although a higher dosage rate may be required to match the performance. Li et al. (2004) utilised waste tyres in two forms (fibres and chips) in concrete. They reported that the performance of concrete dosed with fibres rather than chips was better in terms of strength and stiffness (Li et al., 2004). Ghailan (2005) used waste industrial fibres as aggregate replacement in a concrete mix and reported that the stiffness of the reinforced concrete was higher than that of plain concrete, and a comparatively high corrosion resistance against salts and acids was achieved. Neocleous et al. (2006) evaluated the flexural properties of concrete members reinforced with recycled steel fibres from waste tyres and concluded that the use of these fibres had a great effect on improving the post-peak behaviour of the FRC. Meddah and Bencheikh (2009) investigated the mechanical properties of waste metallic and polypropylene fibres of various lengths. They found that, for waste fibre additions of more than $1.5 \%$ volume fraction of the concrete, the compressive strength of the composite concrete decreased. Meddah and Bencheikh (2009) also reported that a mixture of waste fibres of differing lengths produced the best load-carrying capacity and flexural properties. Aiello et al. (2009) also studied the mechanical properties of concrete reinforced with recycled steel wires from waste tyres; the results obtained using waste fibres were comparable to those using industrial steel fibres and might thus be a promising candidate for use in FRC (Aiello et al., 2009). Jala (2012) reported an increased concrete compressive strength using recovered waste fibres from milling and machining. Recently, Jang et al. (2014) investigated the influence of adding thin film transistor liquid crystal display (TFT-LCD) waste glass with an appropriate ratio of activator on binder in mortar. The obtained results showed that utilising TFT-LCD as an admixture decreased alkali-silica reaction expansion and enhanced the workability and compressive strength of the mortars (Jang et al., 2014).
In the current research, 105 specimens were prepared and the viability of replacing industrial steel fibres with waste steel wires was investigated using two types of fibre in structural lightweight concrete. Compression, tensile, flexural and impact tests were conducted on $28 \mathrm{~d}$ old waste steel fibre reinforced concrete and concrete reinforced with commercial steel fibres. This paper presents the results of the experimental programme.

\section{Experimental investigation}

\section{Cement matrix}

Ordinary type 2 Portland cement (ASTM C150) with a bulk density of $1160 \mathrm{~kg} / \mathrm{m}^{3}$ was used for all the concrete mixtures. Perlite aggregate with a bulk density $93 \mathrm{~kg} / \mathrm{m}^{3}$ and $5 \mathrm{~mm}$ maximum size was used. The fine aggregate was natural river sand with a specific gravity of 1.52 and maximum size of $5 \mathrm{~mm}$. Both sand and perlite aggregates were batched in dry conditions. A commercial liquid super silica gel (SSG) at a constant supply of $8 \%$ of the cement content was used in all the samples.

\section{Fibres}

Two types of steel fibres were used - waste steel wires and commercial hooked-end steel fibres. Waste steel wires found as such constitute the main waste material found in the construction sites in which steel reinforcement as well as formworks were highly used.

The sizes of both types of fibre were made similar in order to make the results comparable. The length and diameter of the industrial steel fibres were $50 \mathrm{~mm}$ and $1.2 \mathrm{~mm}$ respectively whereas the length and diameter of the waste steel wires were $50 \pm 10 \mathrm{~mm}$ and $1.2 \mathrm{~mm}$ respectively. The density of the fibres was approximately $7850 \mathrm{~kg} / \mathrm{m}^{3}$ and their tensile strength $1100 \mathrm{MPa}$. Regarding the actual shape of the fibres, cut waste steel wires were used as a comparison against virgin hooked-end steel fibres (Figure 1). The percentages of reinforcing fibres examined were $0 \cdot 25 \%, 0 \cdot 50 \%$ and $0 \cdot 75 \%$ volume fractions of the concrete.

\section{Mixture composition}

Lightweight perlite concrete - the volumetric mixing of cement, sand, perlite aggregate, steel fibres, water and SSG - was used for the preparation of all the samples. For all mixtures, a water/ cement (w/c) ratio of 0.4 was used while the amount of SSG was constant. Table 1 details the mix proportions. The first four letters of the mix name indicate the type of fibre used - waste steel wires (WFRC) or industrial steel fibres (SFRC); the number following symbolises the fibre content in volume per cent.

To prepare the lightweight aggregate fibre reinforcement, perlite and sand were first dry mixed for $1 \mathrm{~min}$. Then, cement was added to the mixer while running and mixing was continued for another minute. During the mixing operation, the fibres were added and all the materials were mixed for another $2 \mathrm{~min}$. The required amount of a mixture containing water and SSG was then slowly added to the mixer, while mixing was continued for $3 \mathrm{~min}$. Specimens were 


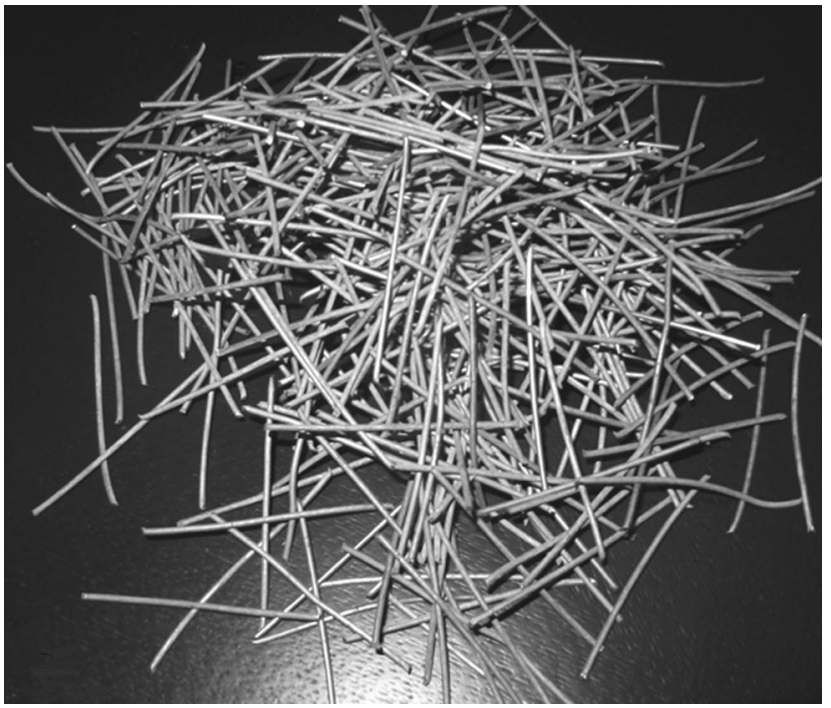

(a)

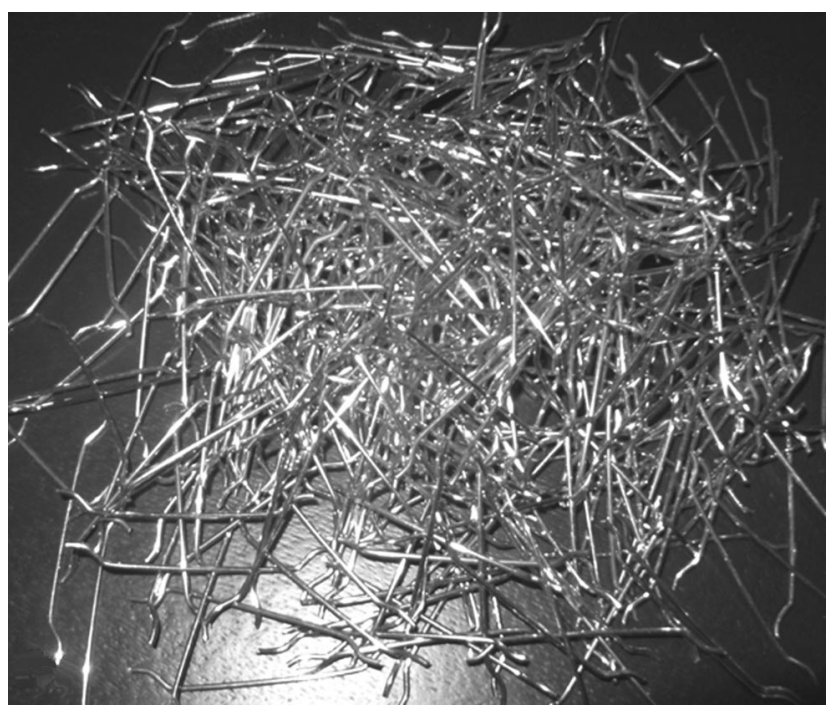

(b)

Figure 1. (a) Cut waste steel wires; (b) standard hooked-end steel fibres formed by pouring at least three layers of concrete into moulds. Once the moulds were full, the concrete specimens were vibrated for a period of $8-12 \mathrm{~s}$ to ensure good compactness.

The specimens were kept in the laboratory for $24 \mathrm{~h}$ under constant ambient temperature. Then, all the specimens were stored in a water tank at a constant temperature of $20 \pm 2^{\circ} \mathrm{C}$ for $28 \mathrm{~d}$, until the day of the experiments.

\section{Test method}

From each mixture, three samples were tested after $28 \mathrm{~d}$ of curing. A total of 105 cubic, cylindrical, prismatic and disc specimens were prepared for subsequent testing.

\section{Compression test}

A total of 21 cubic specimens of dimensions $100 \times 100 \times$ $100 \mathrm{~mm}$ were prepared for compression testing according to ASTM C39-03 (ASTM, 2003). The tests were performed using a digital automatic testing machine and a load rate of $0 \cdot 15 \mathrm{MPa} / \mathrm{s}$.

\section{Splitting tensile test}

A total of 21 cylindrical specimens $(150 \times 300 \mathrm{~mm})$ were prepared for splitting tensile testing conforming to ASTM C496-04 (ASTM, 2004). The tests were performed using a digital automatic testing machine with a load rate of $0.7 \mathrm{MPa} / \mathrm{min}$. A suitable jig was used to position the concrete cylinder: as loading started, the centre of jig, the centre of specimen and the centre of thrust of the spherical bearing block were aligned.

The splitting tensile strength $T$ of the specimens was calculated as

$$
T=2 P / \pi l d
$$

where $P$ is the maximum applied load indicated by the testing machine, $l$ is the length of the cylinder and $d$ is its diameter.

\section{Flexural test}

Flexural tests were conducted on 21 prismatic specimens with dimensions of $500 \times 100 \times 100 \mathrm{~mm}$ in accordance with ASTM C1018-97 (ASTM, 1997). A universal three-point loading

\begin{tabular}{lcccccc}
\hline Mix & Perlite & Sand & Cement & $\begin{array}{c}\text { Volume fraction } \\
\text { of fibre: } \%\end{array}$ & W/C & SSG: \% \\
\hline Plain & 2 & 1 & 2 & 0.00 & 0.4 & 8 \\
WFRC0.25 & 2 & 1 & 2 & 0.25 & 0.4 & 8 \\
WFRC0.50 & 2 & 1 & 2 & 0.50 & 0.4 & 8 \\
WFRC0.75 & 2 & 1 & 2 & 0.75 & 0.4 & 8 \\
SFRC0.25 & 2 & 1 & 2 & 0.25 & 0.4 & 8 \\
SFRC0.50 & 2 & 1 & 2 & 0.50 & 0.4 & 8 \\
SFRC0.75 & 2 & 1 & 2 & 0.75 & 0.4 & 8
\end{tabular}

Table 1. Volumetric mixes of FRC specimens 
machine of $1000 \mathrm{kN}$ loading capacity was employed. The loadcarrying capacities and mid-point displacements of the specimens were recorded. The rate of increasing net mid-span deflection was adjusted to $0 \cdot 1 \mathrm{~mm} / \mathrm{min}$. Load-deflection curves were then plotted and the magnitudes of toughness indices $\left(I_{5}, I_{10}\right.$ and $\left.I_{20}\right)$ and residual strength factors $\left(R_{5,10}\right.$ and $\left.R_{10,20}\right)$ were evaluated. The toughness indices were calculated by determining the area under the load-deflection curves up to the predetermined deflections as proposed in ASTM C1018-97 and dividing it by the area up to the first-crack deflection.

\section{Impact test}

A total of 42 disc specimens (diameter $150 \mathrm{~mm}$ and thickness $640 \mathrm{~mm}$ ) were prepared for impact testing according to the recommended method proposed by ACI Committee 544 (ACI, 1999). Due to the use of fibres of $50 \mathrm{~mm}$ length, the test specimens were cut from a full-size cylinder to minimise preferential fibre alignment (ACI, 1999; Nataraja et al., 2005).

According to the drop weight impact test method, the disc specimens were struck by repeatedly dropping a $4.5 \mathrm{~kg}$ hammer from a height of $45 \mathrm{~cm}$. The load was transferred from the hammer to the specimen through a $64 \mathrm{~mm}$ steel ball placed at the centre of the disc specimen (Nataraja et al., 2005). The initial and ultimate failure points were evaluated, testifying the impact resistance of the specimens: the initial failure point is the number of blows required to cause the first visible crack in the specimen and the ultimate failure point is the number of blows after which the disc specimen fails and comes into contact with three of the four steel lugs of the test equipment (Badr et al., 2006; Nataraja et al., 2005). The impact load was time independent.

\section{Results and discussion}

\section{Compressive strength}

Figure 2 shows the compressive strength results for WFRC specimens, SFRC specimens and plain concrete specimens. The compressive strength of the perlite lightweight concrete used for the plain and FRC specimens was $18 \cdot 86-24.26 \mathrm{MPa}$ and its density was $1708 \cdot 5-1800 \cdot 0 \mathrm{~kg} / \mathrm{m}^{3}$. This type of concrete is known as structural lightweight concrete (ASTM, 2002). It was found that an increase of waste wire content and industrial steel fibre from 0 to $0 \cdot 25 \%$ increased the compressive strength of WFRC and SFRC specimens by approximately $5 \%$ and $18 \%$ respectively compared with the plain concrete specimens. The compressive strength of the FRC specimens with $0.50 \%$ volume fraction of the concrete increased significantly, reaching peak values of 24.08 MPa and 24.84 MPa for WFRC and SFRC respectively.

However, compared with the plain concrete, the compressive strength of both WFRC and SFRC decreased (by $8 \%$ and 3\% respectively) when further increasing the fibre or wire content from $0 \cdot 50 \%$ to $0 \cdot 75 \%$. It is worth noting that the compressive strength for the highest level of fibre content $(0 \cdot 75 \%)$ is lower than that of the plain concrete. This decrease in compressive strength for this fibre content may be due to difficulties in scattering and condensing the fibres in the concrete. This phenomenon has been discussed elsewhere (Hassanpour et al., 2012).

\section{Splitting tensile strength}

The splitting tensile strength results for plain concrete and FRC specimens are shown in Figure 3. As can be seen, the addition of fibres greatly increased the splitting tensile strengths. Compared with the plain concrete specimens, the splitting tensile strengths of WFRC and SFRC specimens increased by an average of $28 \%$ and $26.33 \%$ respectively for fibre ratios of $0.25 \%, 0.50 \%$ and $0 \cdot 75 \%$. Similarly, Gao et al. (1997) reported that an addition of steel fibre from 0 to $2 \%$ volume fraction of the concrete increased the splitting tensile strength from 4.95 to $8.80 \mathrm{MPa}$. Ultimately, the increase in splitting tensile strength is based on the connection between the fibres and the cement matrix. In fact, adding fibres at only $0 \cdot 25 \%$ increases the splitting tensile strength significantly. This shows that, with any addition of fibres, the

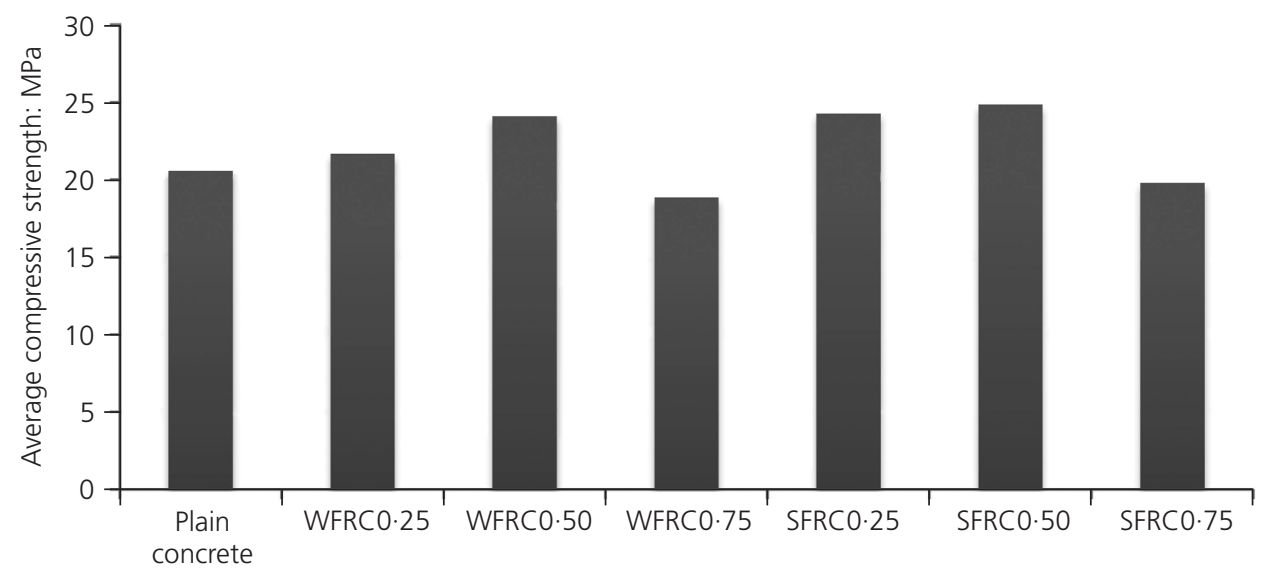

Figure 2. Average compressive strength of WFRC, SFRC and plain specimens 


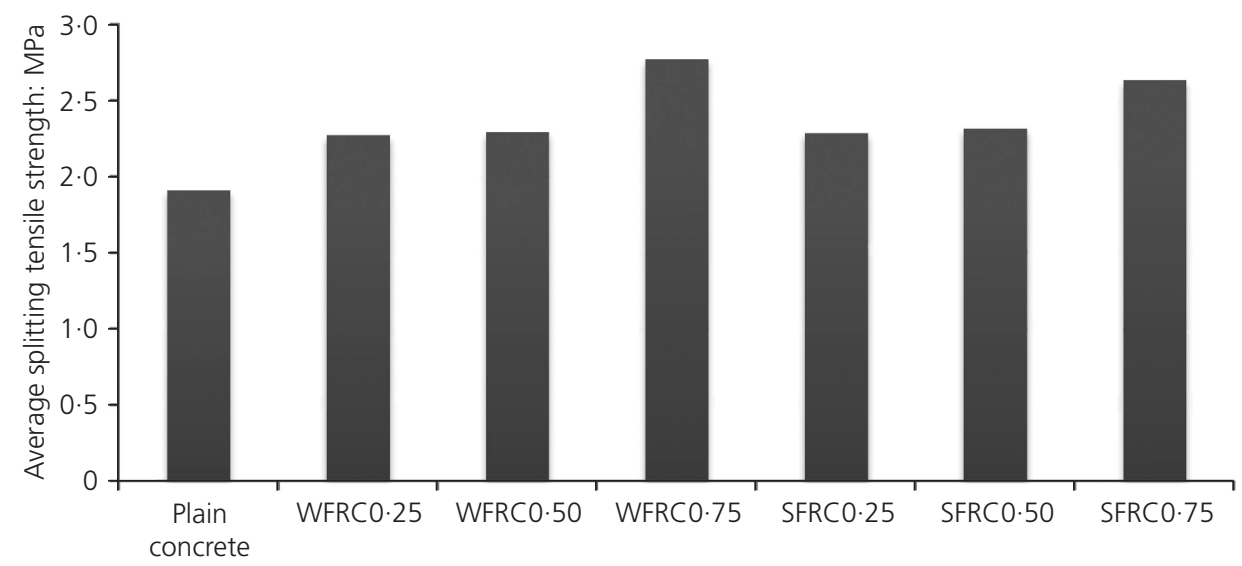

Figure 3. Average splitting tensile strength of WFRC, SFRC and plain specimens

splitting tensile strength of FRC specimens will be improved remarkably, as noted by Shafigh et al. (2011) and Balendran et al. (2002).

Figure 4 shows the plain concrete rupture with brittle failure following the tensile strength peak. Conversely, the FRC specimens showed only small surface cracks in the direction of the load transfer, across the length of the specimens. Fibres thus play

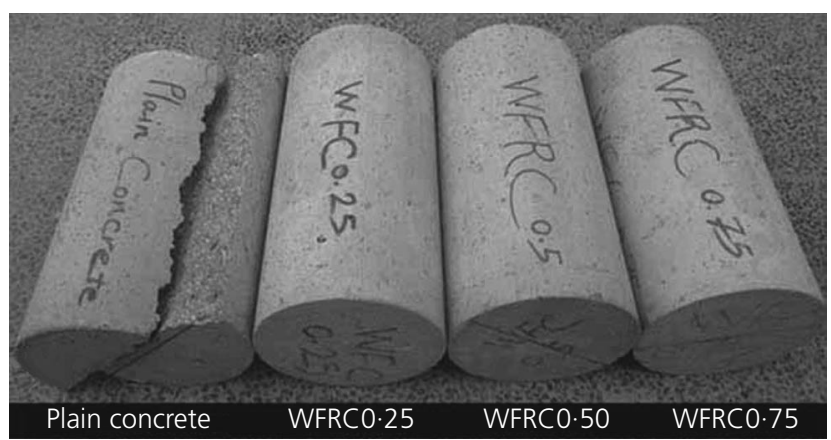

(a)

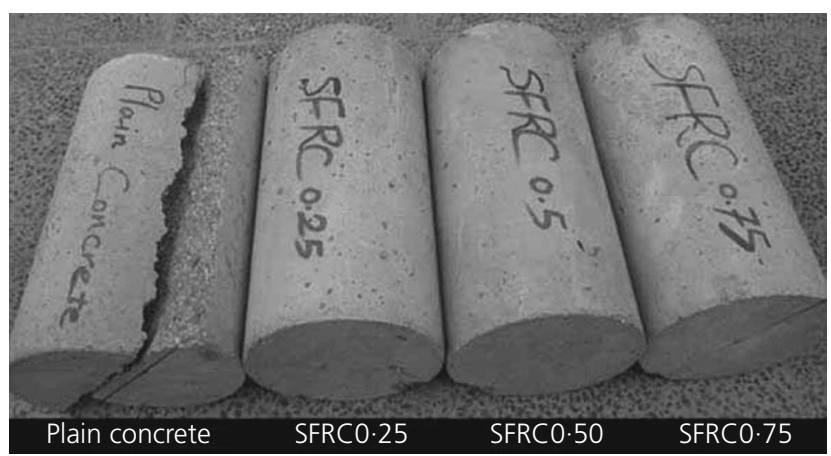

(b)

Figure 4. Comparison of failure patterns of plain and FRC specimens after splitting tensile strength: (a) WFRC; (b) SFRC a significant role in making concrete capable of resisting crack propagation.

\section{Flexural strength}

The flexural test results of the different mixes are summarised in Table 2. Each result is the mean value recorded from three tests. All values of the first-crack strength (FCS) of FRC specimens were higher than those of the plain concrete specimens. Similarly, the first-crack deflections were higher with increasing the fibre percentage due to increased ductility of the FRC specimens. The maximum FCS of the FRCs is $3.745 \mathrm{MPa}$, which is $40 \%$ higher than the FCS of the plain concrete specimens; this value relates to WFRC $0.75 \%$. The corresponding maximum FCS of SFRC is approximately $29 \%$ higher than that of the plain concrete.

In order to determinate the energy absorption capability and toughness of flexural specimens, the toughness indices and residual strength factors were assessed as suggested in ASTM C1018-97 (ASTM, 1997). The toughness indices relate to the ability of FRC specimens to transfer stresses across a cracked section and this is considered as their energy absorption capacity. Table 2 shows that increasing the volume fraction of fibres increases the toughness indices for both WFRC and SFRC specimens. The toughness indices of WFRC specimens are higher than those of SFRC specimens at $0.25 \%$ and $0.75 \%$ fibre contents, while the values are very similar for both concrete types for $0.50 \%$ fibre content.

Moreover, the toughness indices of WFRC0.50 and WFRC0.75 are almost equal. This reveals that the post-peak area in the loaddeflection curves increased in a proportional manner compared with the pre-peak area. In contrast, the toughness indices of SFRC 0.50 are significantly higher than those of SFRC 0.25 or SFRC0.75. Therefore, in the case of $0.50 \%$ fibre content, the post-peak area increased significantly compared with the pre-peak area, whereas in other SFRCs the post-peak area increased proportionally to the pre-peak area (Figures 5 and 6). 


\begin{tabular}{|c|c|c|c|c|c|c|c|c|}
\hline & \multirow[t]{2}{*}{$V_{\mathrm{f}}: \%$} & \multirow{2}{*}{$\begin{array}{c}\text { First-crack } \\
\text { strength: } \mathrm{MPa}\end{array}$} & \multirow{2}{*}{$\begin{array}{c}\text { First-crack } \\
\text { deflection: mm }\end{array}$} & \multicolumn{3}{|c|}{ Toughness indices } & \multicolumn{2}{|c|}{ Residual strength factors } \\
\hline & & & & 15 & $I_{10}$ & $I_{20}$ & $R_{5,10}$ & $R_{10,20}$ \\
\hline Plain & 0.00 & 2.676 & 0.642 & - & - & - & - & - \\
\hline WFRC0.25 & 0.25 & $3 \cdot 027$ & 0.853 & $2 \cdot 58$ & $4 \cdot 14$ & $6 \cdot 56$ & $31 \cdot 2$ & $24 \cdot 2$ \\
\hline WFRC0.50 & 0.50 & $3 \cdot 312$ & 1.087 & $4 \cdot 26$ & $7 \cdot 31$ & $11 \cdot 47$ & $61 \cdot 0$ & $41 \cdot 6$ \\
\hline WFRC 0.75 & 0.75 & $3 \cdot 745$ & 0.946 & $4 \cdot 13$ & $7 \cdot 28$ & $11 \cdot 91$ & $63 \cdot 0$ & $46 \cdot 3$ \\
\hline SFRC0.25 & 0.25 & $3 \cdot 515$ & 0.855 & $2 \cdot 29$ & $3 \cdot 61$ & $5 \cdot 85$ & $26 \cdot 4$ & $22 \cdot 4$ \\
\hline SFRC0.50 & $0 \cdot 50$ & $3 \cdot 295$ & 1.005 & $4 \cdot 65$ & 8.09 & $12 \cdot 00$ & $68 \cdot 8$ & $39 \cdot 1$ \\
\hline SFRC0.75 & 0.75 & $3 \cdot 440$ & $1 \cdot 480$ & $3 \cdot 42$ & 4.95 & $6 \cdot 67$ & $30 \cdot 6$ & $17 \cdot 2$ \\
\hline
\end{tabular}

Table 2. First-crack strength, first-crack deflection, toughness indices and residual strength factors of specimens in bending specimens

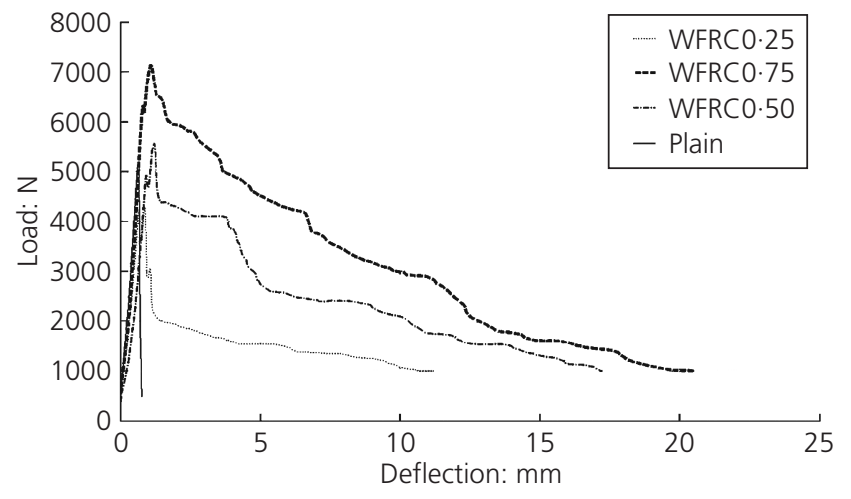

Figure 5. Flexural load-deflection curves of WFRC and plain specimens

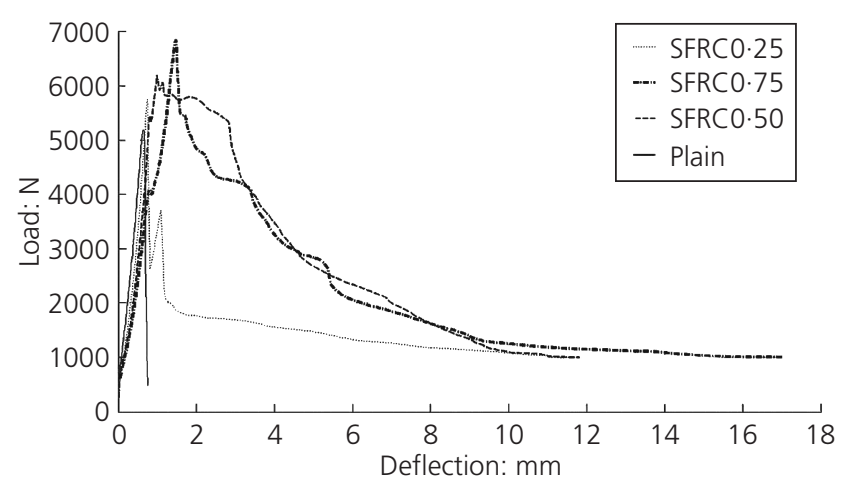

Figure 6. Flexural load-deflection curves of SFRC and plain specimens

The residual strength factors represent the average level of strength retained after occurrence of the first crack as a percentage of the FCS over a predetermined deflection interval (ASTM, 1997). Table 2 shows that higher residual strength factors are achieved with increasing fibre content, and concrete specimens reinforced with waste steel wires produced higher residual strength factors than their industrial steel fibre counterparts.

Figures 5 and 6 show average load-deflection curves for different percentages of fibre content for WFRC and SFRC specimens respectively. The plain specimens without fibre tested under bending action failed in a brittle manner once the peak load was reached. They broke into two pieces suddenly, and the small area under the load-deflection curve illustrates the small amount of energy absorbed. The FRC specimens exhibited ductile behaviour due to the characteristic bond between the fibres and the cement. Analysis of the load-deflection curves reveals that the first crack was followed by a sharp drop in the load-carrying capacity and then a descending curve follows, leading to ultimate failure. The results show that the ultimate deflection of specimens WFRC0.75 and SFRC0.75 is respectively about 32.0 and 26.5 times greater than that of the plain concrete specimens.

The absolute toughness index (or absorbed energy) is assessed by estimating the total area under the load-deflection curve up to ultimate failure. Figure 7 shows that all the indices of the FRCs are higher than those of plain concrete. WFRC0.75 shows the highest energy absorption, with an average value of $6276.63 \mathrm{~kg} \mathrm{~mm}$, about 28.5 times higher than that of plain concrete. The absorbed energy of SFRC0.75 is $3585.994 \mathrm{~kg} \mathrm{~mm}$, considerably lower than that achieved by WFRC $0 \cdot 75$.

\section{Impact strength}

The values of first-crack resistance and ultimate resistance were also averaged, having considered six specimens for each mixture. As shown in Table 3, the number of blows required to cause the first visible crack and the number of blows needed for ultimate failure increase with increasing fibre content. The plain concrete specimens presented brittle behaviour and very low resistance after the initial crack, with specimens taking fewer blows reaching ultimate failure earlier. The FRC specimens were able to bear considerably more blows up to ultimate failure. The increase in post-crack resistance is absolutely dependent on fibre content 


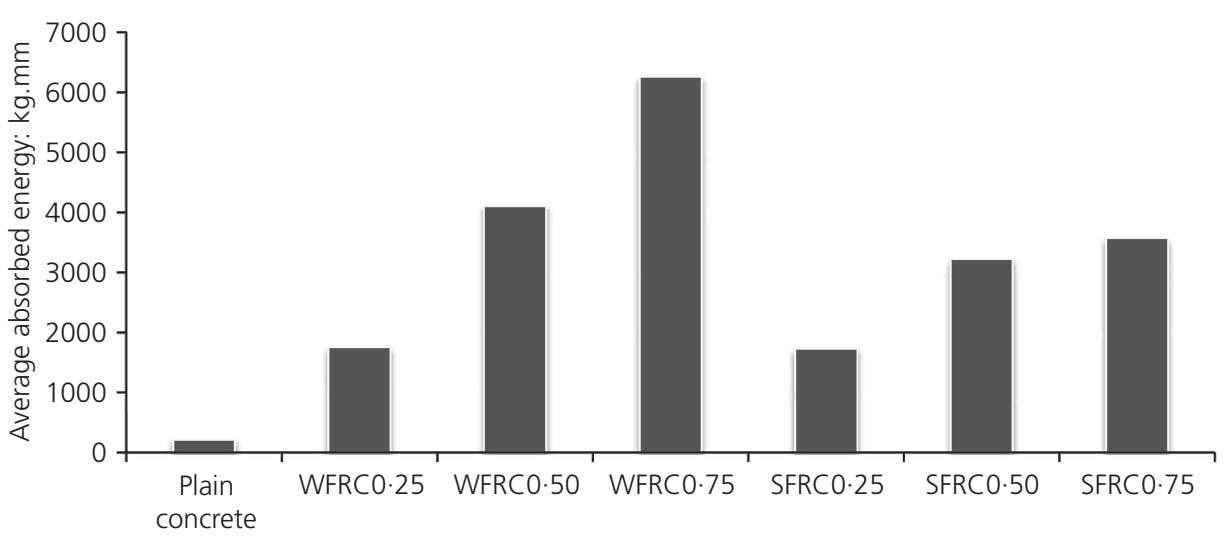

Figure 7. Average amount of absorbed energy by bending samples in kg.mm

\begin{tabular}{|c|c|c|c|c|c|}
\hline & $\begin{array}{l}\text { First-crack resistance } \\
\text { (FCR): } \\
\text { number of blows }\end{array}$ & $\begin{array}{l}\text { Ultimate resistance } \\
\text { (UR): } \\
\text { number of blows }\end{array}$ & $\begin{array}{l}\text { Increase in resistance } \\
\text { from FCR to UR: \% }\end{array}$ & FCR FRC $_{\text {F }}$ FCR Plain & U $\mathrm{R}_{\text {FRC }} / \mathrm{UR}_{\text {Plain }}$ \\
\hline Plain & 2 & 3 & $50 \cdot 00$ & - & - \\
\hline WFRC0.25 & 3 & 28 & $833 \cdot 33$ & $1 \cdot 5$ & $9 \cdot 33$ \\
\hline WFRC0.50 & 3 & 36 & $1100 \cdot 00$ & $1 \cdot 5$ & $12 \cdot 00$ \\
\hline WFRC0.75 & 3 & 53 & $1666 \cdot 67$ & $1 \cdot 5$ & $17 \cdot 67$ \\
\hline SFRC0.25 & 3 & 31 & $933 \cdot 33$ & $1 \cdot 5$ & $10 \cdot 33$ \\
\hline SFRC0.50 & 4 & 48 & $1100 \cdot 00$ & $2 \cdot 0$ & $16 \cdot 00$ \\
\hline SFRC0.75 & 4 & 67 & $1575 \cdot 00$ & $2 \cdot 0$ & $22 \cdot 33$ \\
\hline
\end{tabular}

(e.g. $833 \%$ to $1667 \%$ for WFRC specimens and $933 \%$ to $1575 \%$ for SFRC specimens). Consequently, a significant improvement in impact load resistance is essentially achieved by increasing the volume fraction of both types of fibre in structural lightweight concrete.

Because the fibres span across the cracks, the impact energy of hammer blows can be absorbed, crack propagation within the concrete is prevented and splitting of the concrete into small pieces is also minimised. For SFRC specimens, better performance was achieved under impact action: the specimens resisted more blows than the WFRC specimens due to the hooked-end steel fibres and thus further interlocking between the fibres and the concrete. The impact resistance of SFRC0.75 and WFRC0.75 was respectively about 17 and 13 times greater than that of the plain concrete specimens. One way to improve the impact strength of WFRC specimens would be to use a larger amount of steel waste wires, thus increasing the splitting tensile strength.

Upon impact testing, the plain concrete specimens broke into three pieces, implying a brittle failure mode (Figure 8). The FRC specimens presented at least four large polar cracks due to the more uniform stress distribution in the concrete. The width of

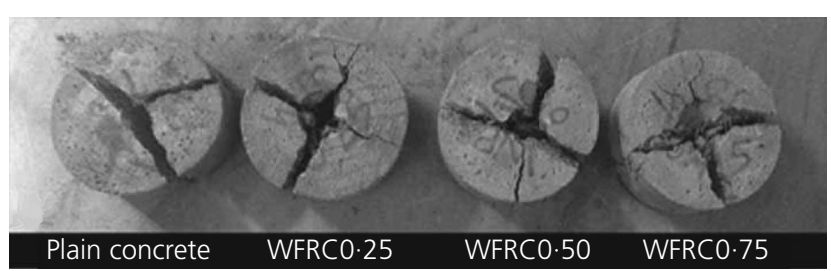

(a)

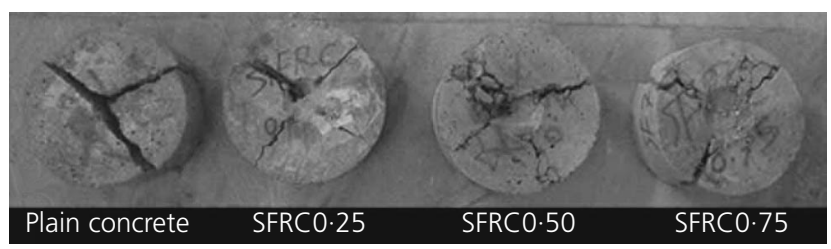

(b)

Figure 8. Comparison of failure patterns of FRC specimens after impact testing: (a) WFRC; (b) SFRC

cracks in the SFRC samples was smaller than those in the WFRC specimens. This again indicates that the SFRC specimens possess higher impact resistance due to the more effective bridging of fibres across the cracks. 


\section{Concluding remarks}

The mechanical properties of structural lightweight concrete reinforced with waste steel wires (WFRC) were experimentally investigated. The results were compared to the mechanical properties of lightweight concrete reinforced with commercial steel fibres (SFRC) and plain concrete.

Incorporating waste wires or industrial steel fibres up to $0 \cdot 50 \%$ volume fraction of concrete in structural lightweight concrete increases the compressive strength. However, the addition of more than $0.50 \%$ volume fraction of concrete decreases the compressive strength. These increasing and decreasing strength trends with respect to fibre content were the same for both types of fibres considered. The FRC specimens showed considerably higher splitting tensile strengths than the plain concrete specimens, even for low volumes of fibres. The overall performance in terms of splitting tensile strength was better in WFRC specimens than SFRC specimens. It is remarkable that even very small quantities of fibres can help in preventing the brittle failure of lightweight aggregate concrete.

The maximum flexural strength and energy absorption was obtained by WFRC0.75 specimens: the energy absorption of WFRC 0.75 was 28.5 times greater than that of plain concrete and $75 \%$ higher than that of SFRC $0 \cdot 75$. Furthermore, the addition of waste steel wires at $0.75 \%$ volume fraction of the lightweight concrete led to an eighteen-fold increase in ultimate impact resistance compared with the plain concrete specimens. While this improved the impact resistance significantly, it was still lower than that of SFRC0.75 due to the hooked shape of the commercial fibres.

In conclusion, the use of waste steel wires is considered suitable for certain applications, acting as micro reinforcement. The direct reuse of such wires is a viable, economic and environmentally friendly method for replacing the more expensive industrial steel fibres.

\section{Acknowledgement}

The authors would like to thank Mrs Lora Zare for her invaluable help in preservation and curing of the concrete specimens.

\section{REFERENCES}

ACl (American Concrete Institute) (1999) ACI 544 2R-89:

Measurement of properties of fibre reinforced concrete. ACI, Farmington Hills, MI, USA.

Aiello MA, Leuzzi F, Centonze G and Maffezzoli A (2009) Use of steel fibers recovered from waste tires as reinforcement in concrete: pull-out behavior, compressive and flexural strength. Waste Management 29(6): 1960-1970.

Alshihri MM, Azmy AM and El-Bisy MS (2009) Neural networks for predicting compressive strength of structural light weight concrete. Construction and Building Materials 23(6): 22142219.

Altun F and Aktas B (2013) Investigation of reinforced concrete beams behavior of steel fiber added lightweight concrete. Construction and Building Materials 38(January): 575-581.

Arisoy B and Wu HC (2008) Material characteristics of high performance lightweight concrete reinforced with PVA. Construction and Building Materials 22(4): 635-645.

Aslani F (2013) Effects of specimen size and shape on compressive and tensile strengths of self-compacting concrete with or without fibres. Magazine of Concrete Research 65(15): 914-929.

ASTM (1997) ASTM C1018-97: Standard test method for flexural toughness and first-crack strength of fiber-reinforced concrete (using beam with third-point loading). ASTM, West Conshohocken, PA, USA.

ASTM (2002) ASTM C330-02a: Standard specification for lightweight aggregates for concrete masonry units. ASTM, West Conshohocken, PA, USA.

ASTM (2003) ASTM C39-03: Standard test method for compressive strength of cylindrical concrete specimens. ASTM, West Conshohocken, PA, USA.

ASTM (2004) ASTM C496-04: Standard test method for splitting tensile strength of cylindrical concrete specimens. ASTM, West Conshohocken, PA, USA.

Badr A, Ashour AF and Platten AK (2006) Statistical variations in impact resistance of polypropylene fibre-reinforced concrete. International Journal of Impact Engineering 32(11): 19071920.

Balendran RV, Zhou FP, Nadeem A and Leung AYT (2002) Influence of steel fibers on strength and ductility of normal and lightweight high strength concrete. Building and Environment 37(12): 1361-1367.

Chanh NV (2004) Steel Fiber Reinforced Concrete. Ho Chi Minh City University of Technology, Ho Chi Minh, Vietnam, pp. 108-116.

Domagala L (2011) Modification of properties of structural lightweight concrete with steel fibers. Civil Engineering and Management 17(1): 36-44.

Duzgun OA, Gul R and Aydin AC (2005) Effect of steel fibers on the mechanical properties of natural lightweight aggregate concrete. Materials Letters 59(27): 3357-3363.

Gao J, Suqa W and Morino K (1997) Mechanical properties of steel fiber-reinforced, high-strength, lightweight concrete. Cement and Concrete Composites 19(4): 307-313.

Ghailan AH (2005) Modified concrete by using a waste material as a coarse aggregate. Proceedings of Construction Research Congress: Broadening Perspectives, San Diego, CA, USA, pp. 217-226.

Ghasemi Naghibdehi M, Mastali M and Sharbatdar MK (2014) Flexural performance of functionally graded RC cross-section with steel and PP fibres. Magazine of Concrete Research 66(5): 219-233.

Hassanpour M, Shafigh P and Bin Mahmud H (2012) Review of lightweight aggregate concrete fiber reinforcement. Construction and Building Materials 37(3): 452-461.

Jala M (2012) Compressive strength enhancement of concrete 
reinforced by waste steel fibers utilizing nano $\mathrm{SiO}_{2}$. MiddleEast Journal of Scientific Research 12(3): 382-391.

Jang HS, Jeon SH, So HS and So SY (2014) A study of the possibility of using TFT-LCD waste glass as an admixture for steam-cured PHC piles. Magazine of Concrete Research 66(4): 196-208.

Kandasamy R and Murugesan R (2011) Fiber reinforced concrete using domestic waste plastics as fibers. Engineering and Applied Science 6(3): 75-82.

Kayali O, Haque MN and Zhu B (2003) Some characteristics of high strength fiber reinforced lightweight aggregate concrete. Cement and Concrete Composites 25(2): 207-213.

Li G, Stubblefield MA, Garrick G et al. (2004) Development of waste tire modified concrete. Cement and Concrete Research 34(12): 2283-2289.

Libre NA, Shekarchi M, Mahoutian M and Soroushian P (2011) Mechanical properties of hybrid fiber reinforced lightweight aggregate concrete made with natural pumice. Construction and Building Materials 25(5): 2458-2464.

Meddah MS and Bencheikh M (2009) Properties of concrete reinforced with different kinds of industrial waste fiber materials. Construction and Building Materials 23(10): 3196 3205.

Mohammadi Y, Singh SP and Kaushik SK (2008) Properties of steel fibrous concrete containing mixed fibers in fresh and hardened states. Construction and Building Materials 22(5): 956-965.

Naaman AE and Reinhardt HW (2003) High performance fiber reinforced cement composites (HPFRCC4). Proceedings of 4th International RILEM Workshop on High Performance Fiber Reinforced Cement Composites (HPFRCC 4), Ann Arbor, MI, USA, pp. 91-133.

Nataraja MC, Nagaraj TS and Basavaraja SB (2005) Reproportioning of steel fiber reinforced concrete mixes and their impact resistance. Cement and Concrete Research 35(12): 2350-2359.

Neocleous K, Pilakoutas H and Waldron P (2006) From used tires to concrete fiber reinforcement. Proceedings of 2 nd International FIB Congress, Naples, Italy.

Pawade PY, Nagarnaik PB and Pande AM (2011) Influence of silica fume in enhancement of compressive strength, flexural strength of steel fibers concrete and their relationship. International Journal of Civil and Structural Engineering 2(1): 43-55.

Sengul O, Azizi S, Karaosmanoglu F and Tasdemir MA (2011) Effect of expanded perlite on the mechanical properties and thermal conductivity of lightweight concrete. Energy and Buildings 43(2-3): 671-676.

Shafigh P, Mahmud H and Jumaat MZ (2011) Effect of steel fiber on the mechanical properties of oil palm shell lightweight concrete. Materials Design 32(7): 3926-3932.

Shah AA and Ribakov Y (2011) Recent trends in steel fibered high-strength concrete. Materials Design 32(8-9): 41224151.

Slater E, Moni M and Alam MS (2012) Predicting the shear strength of steel fiber reinforced concrete beams. Construction and Building Materials 26(1): 423-436.

Süleyman Gökçe H and Şimşek O (2013) The effects of waste concrete properties on recycled aggregate concrete properties. Magazine of Concrete Research 65(14): 844-854.

Tanyildizi H (2008) Effect of temperature, carbon fibers and silica fume on the mechanical properties of lightweight concretes. New Carbon Materials 23(4): 339-344.

Topcu IB (1997) Semi-lightweight concretes produced by volcanic slags. Cement and Concrete Composites 27(1): 15-21.

Wang Y (2010) Fiber and textile waste utilization. Waste Biomass Valorization 1(1): 135-143.

Wang Y, Wu HC and Li VC (2000) Concrete reinforcement with recycled fibers. Materials in Civil Engineering 12(4): 314 319.

Withers PJ and Bhadeshia HKDH (2001) Residual stress, part 1: measurement techniques. Materials Science and Technology 17(4): 355-365.

Wui X, Wu ZM, Zheng JJ, Ueda T and Yi SH (2013) An experimental study on the performance of self-compacting lightweight concrete exposed to elevated temperature. Magazine of Concrete Research 65(13): 780-786.

Yasar E, Atis CD, Kilic A and Gulsen H (2003) Strength properties of lightweight concrete made with basaltic pumice and fly ash. Materials Letters 57(15): 2267-2270.

\section{WHAT DO YOU THINK?}

To discuss this paper, please submit up to 500 words to the editor at journals@ice.org.uk. Your contribution will be forwarded to the author(s) for a reply and, if considered appropriate by the editorial panel, will be published as a discussion in a future issue of the journal. 